\title{
No causal effect of unemployment on smoking? A German panel study
}

\author{
Reinhard Schunck, Benedikt G. Rogge
}

\begin{abstract}
Objectives This study analyses the effects of different unemployment durations on smoking behaviour in Germany by investigating smoking take-up, relapse, quitting and smoking intensity. Methods Longitudinal data from the German Socio-Economic Panel from the years 1998, 2001, 2002, 2004, 2006, and 2008 were used to examine the effect of unemployment (52,940 observations from 17,028 respondents, aged 17-65 years). Unemployment duration was measured at $1-6,7-12,13-24$, and 24+ months. Effects were estimated using zero-inflated negative binomial regressions and fixed effects logistic panel regressions. Results The zero-inflated negative binomial regression models suggest that the likelihood of smoking increases with unemployment, while smoking intensity is not affected. However, fixed effects logistic regression models demonstrate that unemployment is neither a significant predictor for taking up smoking, relapsing, nor quitting. Conclusions The results indicate that in Germany, there is no direct causal effect of unemployment on smoking behaviour. The observed relationship between smoking and unemployment appears to be driven by stable, unobserved differences between employed and unemployed respondents.
\end{abstract}

Keywords: Health behaviour, Smoking, Unemployment, Longitudinal analysis, Causality, Fixed effects

\section{INTRODUCTION}

The negative health consequences of unemployment have been documented extensively (Bartley et al. 2006; Kroll and Lampert 2011; Thomas et al. 2005). Moreover, as lifetime unemployment is significantly more prevalent in lower social strata (Chan and Goldthorpe 2007), it may constitute an important mechanism in the genesis of social inequalities in health (Umberson et al. 2008). Yet, the relationship between health-related behaviours and unemployment is still under-researched. This particularly applies to smoking, which is associated with numerous forms of cancer and cardiovascular diseases and is by far the strongest preventable risk factor for premature mortality (Becker 2001; Schneider 2007).

Cross-sectional studies have established that the unemployed are significantly more likely to smoke than the employed and the average population (De Vogli and Santinello 2005; Schunck and Rogge 2010). Yet, this association can be interpreted as both a selection from poor health into unemployment and a causal effect of unemployment as determining poor health (Bartley 1988). In this study, we only deal with the consequences of unemployment on smoking behaviour, not vice versa. However, to assess these effects, longitudinal evidence is required as cross-sectional studies cannot distinguish selection and causal effects. Previous longitudinal studies deliver contradicting evidence. 
While there is evidence that unemployment increases smoking probability in Sweden (Hammarstrom and Janlert 2003), studies from the US (Bolton and Rodriguez 2009; Falba et al. 2005; Gallo et al. 2005; Ryan et al. R. 1996) and Britain (Montgomery et al. 1998; Morriset al. 1992) report mixed results, whereas no evidence for such a relation is found in Finland (Virtanen et al. 2008) and Denmark (Osler 1995). German longitudinal studies on this research question are, till this day, altogether missing.

Of course, the reported divergences between previous studies might trace back to country-specific effects and welfare state arrangements (Bambra and Eikemo 2009). However, they may also go back to differences in methodology and data use. The central research question that is still at stake is whether or not unemployment exercises a causal effect on smoking behaviour. As we argue, in order to deliver a more precise estimation of the effects of unemployment on smoking, one needs to consider the following aspects: first, possible differential effects of different unemployment durations should be taken into account. Second, accurate data on unemployment duration are needed and continuous unemployment is to be distinguished from discontinuous work biographies. Third, it is necessary to investigate the effects of unemployment not only on smoking probability but also more precisely on take-up, quitting, relapsing and smoking intensity so as to specify the behavioural consequences of unemployment. Fourth, the availability of longitudinal data calls for the application of statistical methods which take full advantage of the data (Kroll and Lampert 2011; Wooldridge 2010). In our view, here, fixed effects logistic regressions constitute an analytically powerful instrument to do so, which, to our knowledge, have not yet been implemented in the analysis of the relation between unemployment and smoking.

Attempting to explain the negative health consequences of unemployment, scholars have principally drawn on stress theory (Pearlin 1989) which we also used to formulate the hypotheses of our study. According to stress theory, unemployment operates as a source of psychological distress that impacts health either directly, e.g. through cortisol responses, or indirectly, notably through health behaviours (Dickerson and Kemeny 2004; Siegrist 2000b). In order to reduce the psychological distress thus emerging, individuals may draw on potentially health-damaging behaviours such as smoking (Siegrist 2000a). From these assumptions, we derived the following hypotheses: (1) unemployment increases the likelihood of smoking, (2) unemployment increases smoking intensity, (3) unemployment decreases the likelihood to quit smoking, and (4) unemployment increases the probability to relapse.

\section{METHODS}

\section{Data}

This study is based on data from the German Socio-Economic Panel (SOEP) (Wagner et al. 2007). The SOEP is an on-going, longitudinal survey of German households with more than 20,000 individual respondents. It has been conducted annually since first administered in 1984. It covers a wide range of topics, including detailed information on labour market integration, socio-economic position, as well as household and family composition. Respondents remain in the survey until they drop out, but attrition is comparably low (Kroh 2010).

As for the dependent variables of our study, the SOEP provides self-reported information on smoking behaviour in the years 1998, 2001, 2002, 2004, 2006, and 2008. Respondents were asked whether they currently smoke, whether they used to smoke, and, if they smoke, how many cigarettes they smoke per day. Based on these measurements, four time-varying variables have been created: (a) smoking status, a binary variable $(0,1)$ indicating whether a person smokes or not, (b) smoking intensity, assessed through the number of cigarettes a person smokes per day, (c) smoking cessation, a 
binary variable $(0,1)$ indicating the absence of smoking in wave $t$ amongst respondents who reported to smoke in wave $t-1$, and $(d)$ smoking relapse, a binary variable $(0,1)$ indicating the restart of smoking among former smokers.

As for the main independent variable, the SOEP includes detailed information on employment status on a monthly basis, which allowed to reconstruct the exact duration of continuous, uninterrupted unemployment spells. We created four dummy-variables. Short-term unemployment is measured in stages of 1-6 months of unemployment and 7-12 months; long-term unemployment as 13-24 months and 24 months or more.

Further, control variables are the respondents' gender, age, years in education, marital status, employment status [full time, part time and marginal employment, which describes an atypical employment form in Germany usually with fixed term contracts and low wages (up to 400/800 € per months)], migration status, the number of persons in the household, number of children in the household, the annual net household income (divided by 1,000, inflation adjusted, and OECD equivalised), subjective health (very good, good, satisfactory, poor, bad), whether or not a respondent lives in East-Germany, as well as year dummies. Analysis of multicollinearity among the independent variables showed acceptable values (mean variance inflation factor $=7.19$, highest condition number $=18.49$ ). We restricted our sample to employed and unemployed respondents of working age (18-65 years). All observations with missing values were excluded from the analyses. This leaves us with 17,028 respondents (and 52,940 observations) for whom we have information on all the variables (see Table 1). The data for the analyses are unbalanced with an average of 2.5 observations per individual.

\section{Statistical analysis}

In the analysis of count data, such as the number of cigarettes per day, linear regression analyses can result in inconsistent, inefficient, and biased estimates (Long 1997). We therefore chose a count model to analyse our data. Since preliminary analysis suggested that we face both overdispersion, meaning that the variance is greater than the mean, and excess zeros, a zero-inflated negative binomial regression appeared most suited (Long 1997). A Vuong test of the zero-inflated model versus the standard negative binomial model $(z=97.48)$ also supports the model choice. The zero-inflated negative binomial regression model comprises a two stage process: a binary model (a logistic regression) estimates the probability of a zero count (i.e. not to smoke) and a second model (a negative binomial regression) estimates the number of cigarettes a person smokes given that this person is a smoker. Two coefficients are thus obtained for each specified predictor. An alternative to zero-inflated models are hurdle models, which also model a two-stage process but differ in their assumptions on the possibility of a zero in the conditional event count (Zorn 1998). However, the results of this study do not depend on the model choice. Both models, the zero-inflated negative binomial and the negative binomial hurdle model (not reported here), produce similar results.

With respect to the analysis of unemployment and smoking, one should not ignore attrition effects since both might be linked with longitudinal non-responses (Cohen and Duffy 2002). To account for a potential bias, we therefore implemented a longitudinal weighting scheme. The weights were computed as the product of a respondent's initial sampling probability multiplied by the inverse of all subsequent staying probabilities. The staying probabilities were computed via logit models predicting a successful re-interview in wave $t$ using independent variables from wave $t-1$ (Kroh 2010). As in panel data, individual observations are non-independent, we used robust (Huber-White sandwich) estimators of standard errors taking account of the clustering of observations within respondents (Wooldridge 2010) 
To test the robustness of our findings, we additionally computed fixed effects logistic regression models (also known as conditional logit or change score models) on smoking take-up, relapse and quitting. Fixed effects models investigate how a within-person change in the independent variable is associated with a change in the dependent variable (Wooldridge 2010). In this study, then, the estimated coefficient reflects the expected change in smoking probability, if a respondent changes her or his employment status or unemployment duration, respectively. From the perspective of fixed effects models, the independent variable can be thought of as resembling a treatment effect, with each case serving as its own control. In contrast to other models (e.g. random effects models), which use both variation between and within subjects, fixed effects models exploit only variation within subjects. As a result, the estimates are not susceptible to bias due to omitted time-constant variables (Kroll and Lampert 2011; Wooldridge 2010). This is a major advantage, because it means that all time-constant characteristics are controlled for. However, because fixed effects models only use individual observations that experience a change both in the dependent variable and in the independent variable, sample size and efficiency are reduced. Moreover, since a change in an independent variable is necessary to estimate the variable's effect, time-constant predictors, like gender and ethnicity, cannot be included in the analysis. This extends to variables which can possibly change, like education, but for which there is (too) little variation within respondents. If interest particularly lies on such characteristics, then the application of fixed effects models is infeasible. However, when interest lies in investigating the effect of predictors that change over time, like unemployment, fixed effects models offer an invaluable advantage, since they control for all time-constant characteristics, whether measured or not. The analyses were carried out using Stata 12.1 software.

\section{RESULTS}

Table 1 displays the descriptive statistics for the variables in this study. Column 2 presents descriptive statistics for the respondents $(\mathrm{N})$ in the sample, whereas the other columns present information on the observations $(\mathrm{N} \mathrm{x} \mathrm{t).} 52.12 \%$ of the 17,028 respondents are male. The overall average age is 41.97 years. $73.22 \%$ of the respondents were employed full time in at least one wave, $23.84 \%$ were employed part-time, $10.54 \%$ were marginally employed, and $15.29 \%$ of the respondents experienced unemployment at least once. The last column shows that the average duration of a period of unemployment is 21.36 months, whereas the median is only 14 months. Among all respondents, $40.73 \%$ report to smoke at least in one wave of the survey. The average number of cigarettes is approximately 14.07 per day. Columns 4 and 5 show the well-known cross-sectional association between unemployment and smoking as both the percentage of smokers (48.94\%), and the average number of cigarettes smoked per day (17.08) is higher among the unemployed than amongst employed respondents ( $33.34 \%$ and 16.60 , respectively).

Table 2 presents the results of the zero-inflated negative binomial regressions for the number of cigarettes smoked per day. The lower part of the table contains the estimated coefficients (odds ratios) of the binary model, predicting the chance of not smoking. The upper part of Table 2 presents the estimates of the coefficients (rate ratios) from the negative binomial model, predicting the actual number of cigarettes smoked per day, conditional upon the binary estimation. 
Table 1 Descriptive statistics on smoking and demographic characteristics (SOEP 1998-2009)

$\begin{array}{cccc}\text { Respondents }^{\text {a }} & \text { All observations } & \text { Observations, } & \text { Observations, } \\ (\mathrm{N}=17,028) & (\mathrm{N} \times t=52,940) & \text { employed } & \text { unemployed } \\ & & (\mathrm{N} \times t=48,712) & (\mathrm{N} \times t=4,228)\end{array}$

Mean / \%

SD $\quad$ Mean $/ \%$

SD $\quad$ Mean $/ \%$

SD $\quad$ Mean $/ \%$

SD

Gender (Male $=1$ )

Age

Mean number of observations per respondent

Smoking $($ Yes $=1)$

Number of cigarettes per day

$52.12 \%$

41.97

11.65
1.47

$53.21 \%$

42.61

9.57

2.5

Annual net HH income (1000€, OECD equivalised, inflation adjusted)

$40.73 \%$

14.07

8.92

$34.58 \%$

\section{Employed: Full time}

Employed: Part time

Employed: Marginally

Unemployed

Mean unemployment duration

\begin{tabular}{|c|c|c|c|c|c|}
\hline $73.22 \%$ & $69.34 \%$ & $75.36 \%$ & -- & $\%$ & \\
\hline $23.84 \%$ & $17.26 \%$ & $18.76 \%$ & -- & $\%$ & \\
\hline $10.54 \%$ & $5.41 \%$ & $5.88 \%$ & -- & $\%$ & \\
\hline $15.29 \%$ & $7.99 \%$ & $--\quad \%$ & -- & $\%$ & \\
\hline-- & -- & -- & 21.36 & & 22.90 \\
\hline$--\quad \%$ & $--\quad \%$ & $--\quad \%$ & 29.90 & $\%$ & \\
\hline$--\quad \%$ & $--\quad \%$ & $--\quad \%$ & 16.89 & $\%$ & \\
\hline$--\quad \%$ & $--\quad \%$ & $--\quad \%$ & 20.77 & $\%$ & \\
\hline$--\quad \%$ & $--\quad \%$ & $--\quad \%$ & 32.45 & $\%$ & \\
\hline
\end{tabular}

nemployment duration: 1-6 month

Unemployment duration: 7-12 month

Unemployment duration: 1-2 years

16.65

21.77

9.13

$\begin{array}{rr}53.23 & \% \\ 42.47 & \\ -- & \\ 33.34 & \% \\ 16.60 & \\ 22.42 & \\ 75.36 & \% \\ 18.76 & \% \\ 5.88 & \% \\ -- & \% \\ -- & \\ -- & \% \\ -- & \% \\ -- & \% \\ -- & \%\end{array}$

$53.05 \%$

53.05
$10.58 \quad 44.30$

Unemployment duration: 2 years and more

Source: unweighted, own computations, number of cases based on the multivariate models.

a: Figures in the column for respondents do not add up to $100 \%$ (e.g. employment), as they are aggregated across all observations per respondent. For instance, $15.29 \%$ of the respondents reported being unemployment at least in one wave. 
Table 2 Zero-inflated negative binomial regression on number of cigarettes smoked per day (SOEP 1998-2009)

\begin{tabular}{lcc}
\hline & \multicolumn{2}{c}{ Count } \\
Employed (full-time) & RR & $95 \% \mathrm{CI}$ \\
\cline { 2 - 3 } Unemployed: 1 to 6 months & 0.98 & $(0.93,1.04)$ \\
Unemployed: 7 to 12 months & 1.05 & $(0.97,1.13)$ \\
Unemployed: 1 to 2 years & 1.07 & $(0.99,1.15)$ \\
Unemployed: 2 years and longer & 1.04 & $(0.95,1.15)$ \\
\hline & Binary (smoking $=0)$ \\
& OR & $95 \% \mathrm{CI}$ \\
Employed (full-time) & ref. & $(0.53,0.99)$ \\
Unemployed: 1 to 6 months & $0.72^{*}$ & $(0.50,0.79)$ \\
Unemployed: 7 to 12 months & $0.63^{* * *}$ & $(0.54,0.81)$ \\
Unemployed: 1 to 2 years & $0.66^{* * *}$ & $(0.45,0.95)$ \\
Unemployed: 2 years and longer & $0.65^{*}$ & \\
\hline Respondents (N) & 17,028 \\
Observations (N x $t$ ) & 52,940 \\
Wald chi²(24) & 525.97 &
\end{tabular}

Source: own computations, $95 \%$ confidence intervals in parenthesis.

Also controlled for age, education, marital status, migration background, number of persons in hh, children in hh, annual net hh income (OECD equivalent, inflation adjusted), other forms of employment (part-time and marginally), subjective health, living in East-Germany, period (years).

Vuong test of the zero-inflated model versus the standard negative binomial model: $z=97.48$

OR odds ratios, $\mathrm{RR}$ rate ratios

${ }^{*} p<0.05,{ }^{* *} p<0.01,{ }^{* * *} p<0.001$

The analysis indicates that unemployment, especially long spells of unemployment, is associated with an increase in a person's smoking probability. Since the logit part of the zero-inflated negative binomial model predicts the chance not to smoke, the odds ratios below 1 suggest that the chance to smoke is increased if respondents are unemployed. Specifically, compared to full-time employment, the relative chances not to smoke decrease with unemployment (OR1-6 months $=0.72,95 \%$ CI 0.53-0.99; OR712 months $=0.63,95 \%$ CI $0.50-0.79$; OR $1-2$ years $=0.66,95 \%$ CI $0.54-0.81$; OR2 years and more $=0.65,95 \%$ CI $0.45-0.95$ ). A Wald test for equality of these coefficients does not reject the null hypothesis (Wald $\chi^{2}(3)=0.72$ ). This indicates that there is no significant trend effect, i.e., the probability of smoking is not differentially affected by different unemployment durations. As to smoking intensity, we do not find any significant association with short nor with long unemployment durations. 
Table 3 Fixed effects logistic regression predicting taking up smoking (SOEP 1998-2009)

\begin{tabular}{lcc}
\hline & OR & $95 \% \mathrm{CI}$ \\
\cline { 2 - 3 } Employed (full-time) & ref. & \\
Unemployed: 1 to 6 months & 0.91 & $(0.68,1.21)$ \\
Unemployed: 7 to 12 months & 0.92 & $(0.64,1.32)$ \\
Unemployed: 1 to 2 years & 0.86 & $(0.60,1.23)$ \\
Unemployed: 2 years and longer & 0.81 & $(0.55,1.19)$ \\
\hline Respondents $(\mathrm{N})$ & 2,913 & \\
Observations $(\mathrm{N} \times t)$ & 13,844 & \\
LR Chi ${ }^{2}(20)$ & 554.76 &
\end{tabular}

Source: own computations $95 \%$ confidence intervals in parenthesis. Also controlled for age, marital status, number of persons in $\mathrm{HH}$, children in $\mathrm{HH}$, annual net $\mathrm{HH}$ income (OECD equivalent, inflation adjusted), other forms of employment (part-time and marginally), subjective health, period (years); OR odds ratios; ${ }^{*} p<0.05,{ }^{* *} p<0.01,{ }^{* * *} p<0.001$

Table 4 Fixed effects logistic regression predicting smoking cessation (SOEP 1998-2009)

\begin{tabular}{lcc}
\hline & OR & $95 \%$ CI \\
\cline { 2 - 3 } Employed (full-time) & ref. & \\
Unemployed: 1 to 6 months & 0.88 & $(0.58,1.33)$ \\
Unemployed: 7 to 12 months & 1.02 & $(0.62,1.67)$ \\
Unemployed: 1 to 2 years & 0.97 & $(0.59,1.60)$ \\
Unemployed: 2 years and longer & 0.89 & $(0.53,1.50)$ \\
\hline Respondents $(\mathrm{N})$ & 2,221 & \\
Observations $(\mathrm{N} x t)$ & 9,423 & \\
LR Chi²(19) & 1789.70 &
\end{tabular}

Source: own computations $95 \%$ confidence intervals in parenthesis. Also controlled for age, marital status, number of persons in $\mathrm{HH}$, children in $\mathrm{HH}$, annual net $\mathrm{HH}$ income (OECD equivalent, inflation adjusted), other forms of employment (part-time and marginally), subjective health, period (years); OR odds ratios, ${ }^{*} p<0.05,{ }^{* *} p<0.01,{ }^{* * *} p<0.001$

Table 5 Fixed effects logistic regression predicting smoking relapse (SOEP 1998-2009)

\begin{tabular}{llc}
\hline & OR & $95 \%$ CI \\
\cline { 2 - 3 } Employed (full-time) & ref. & \\
Unemployed: 1 to 6 months & 1.47 & $(0.80,2.71)$ \\
Unemployed: 7 to 12 months & 1.15 & $(0.54,2.47)$ \\
Unemployed: 1 to 2 years & 1.10 & $(0.51,2.38)$ \\
Unemployed: 2 years and longer & 0.98 & $(0.42,2.30)$ \\
\hline Respondents $(\mathrm{N})$ & 1,049 & \\
Observations $(\mathrm{N} x \mathrm{t})$ & 3,691 & \\
LR Chi ${ }^{2}(18)$ & 427.76 &
\end{tabular}

Source: own computations $95 \%$ confidence intervals in parenthesis. Also controlled for age, marital status, number of persons in $\mathrm{HH}$, children in $\mathrm{HH}$, annual net $\mathrm{HH}$ income (OECD equivalent, inflation adjusted), other forms of employment (part-time and marginally), subjective health, period (years); OR odds ratios; ${ }^{*} p<0.05,{ }^{* *} p<0.01,{ }^{* * *} p<0.001$ 
However, the results from the fixed effects logistic regression models predicting smoking take-up, quitting, and relapsing point in a different direction (Tables 3, 4, 5). When controlling for all time-constant unobserved confounders, the association between unemployment and smoking disappears regardless of unemployment duration. In fact, unemployment does not seem to change a person's probability to take up smoking, to quit, or to relapse. Instead, the observable differences between unemployed and employed respondents appear to trace back to systematic, yet unobserved time-constant differences between these unemployed and employed respondents. Additional analyses (not reported here) do not indicate any gender or age differences in the association of unemployment and smoking.

\section{DISCUSSION}

This study had two objectives: to deliver longitudinal evidence on the relationship between unemployment and smoking in Germany and to provide a refined estimation of this association. As to the latter, our study contributes three major insights to the general knowledge on the health consequences of unemployment: first, it takes analysis of the effects of unemployment duration further by closely scrutinising precise periods of unemployment. Second, it differentiates the smoking variable through an analysis of take-up, quitting, relapse and smoking intensity. Third, it applies fixed effects models to the analysis of the unemployment smoking relationship in order to test the assumed causality of the effects more robustly. All three aspects contribute to an improved understanding of the relationship between unemployment and smoking behaviour.

In general, in our data, there is no evidence for any causal effect of unemployment on smoking. Unemployment does not appear to increase smoking probability or intensity. We do find a considerable and significant cross-sectional association between unemployment duration and the probability to smoke in the zero-inflated negative binomial regression model even after controlling for possible confounders. However, in the fixed effects models, unemployment does not appear as a significant predictor of smoking take-up, quitting and relapse. How can these differences in results be explained? The zero-inflated negative binomial model, like any cross-sectional model, pools all observations and bases its effect estimates on comparisons between and within persons. The fixed effects models' estimates on the other hand are based solely on within-person variation. The latter estimation strategy has the advantage that all possible confounders at the person level are automatically accounted for. This suggests that unobserved, stable differences between unemployed and employed persons bring about the observable, cross-sectional association between unemployed and smoking. To put it into other words, people who have a high likelihood of smoking also have a high likelihood of being unemployed, but unemployment itself does not seem to cause smoking.

This finding stands in stark contrast with the widespread assumption that the health-damaging behaviours that many unemployed, in particular long-term unemployed, show are actually produced by the experience of unemployment. But how do we explain the cross-sectional association of unemployment and smoking?

This question takes us back to the well-known debate on selection and causation effects. Regarding the relationship between unemployment and (ill) health, today, most researchers assume a co-existence of selection as well as causation mechanisms to account for it (Bartley 1988). Numerous studies have demonstrated the existence of selection effects in the association of unemployment and health behaviours (Jusot et al. 2008; Leino-Arjas et al. 1999; Ryan et al. 1996). One explanation for the cross-sectional association could indeed consist in smokers being more likely to become unemployed 
than non-smokers. Another form of selection could be a lower re-employment probability in smokers once they are unemployed.

However, the above-described selection mechanisms are still more complicated as they are confounded by socioeconomic characteristics. That is to say that the social stratification in smoking behaviour is mirrored by social stratification in the probability of becoming unemployed (Chan and Goldthorpe 2007). In other words, people from lower socio-economic strata become unemployed more often and at the same time also smoke more often. Thus, there might not only be a direct selection effect of smokers into becoming and remaining unemployed but also an indirect selection effect operating through an individual's socio-economic position (Graham 2002; Kuh et al. 2003). This assumption can also be thought of as a common cause explanation of health inequalities, more precisely as a fundamental cause explanation of health inequalities (Link and Phelan 1996). In this perspective, social stratification produces both social and health inequalities throughout the life course. People from lower social strata are disadvantaged as they are at a greater risk of smoking and being unemployed.

Still, our findings might also diverge from previous studies because of methodological reasons. To our knowledge, no other study has yet implemented fixed effects models to estimate the effect of unemployment on smoking. However, a word of caution is in place regarding the use of fixed effects models. Although these models are an improvement over pooled cross-sectional or random effects models (Wooldridge 2010), their application comes at a price. Their estimation method relies exclusively on within-subject variation. As in our sample, there are comparably few subjects who changed their status in both the dependent and independent variables. The transition probabilities for quitting and taking up smoking are, for instance, only around 10.26 and $4.94 \%$, respectively, in the multivariate sample. As a consequence, the multivariate samples that are used to estimate the fixed effects models are much smaller than the sample used to estimate the (pooled cross-sectional) zero-inflated negative binomial model. Thus, the results of this study need to be scrutinised in studies with larger data.

Finally, we should like to stress that our results do by no means indicate that unemployment is not a serious public health problem. On the contrary, in most Western welfare regimes, the unemployed represent a marginalised group that is highly vulnerable to bad health states. Even if unemployment does not cause people to smoke more often, unemployment and smoking still coincide and smoking certainly represents a severe risk for morbidity and mortality (Becker 2001; Schneider 2007). Thus, health risks still accumulate within the group of the unemployed. Nonetheless, at least for Germany, experiencing unemployment does not seem to be a mechanism which further deepens social inequalities in smoking behaviour over the life course.

These tentative reflections need to be investigated in future research. Most importantly, more longitudinal evidence is needed to disentangle the apparently complex relationship of unemployment and smoking. It may be particularly promising to explore how and if unemployment and smoking are related through a common cause, that is one's position in the social strata, and how this relation unfolds over the life course. People usually start to smoke in adolescence or early adulthood (Edelen et al. 2007). Thus, social and economic circumstances in earlier life stages may be particularly important, as they structure health behaviours, later life experiences, labour market opportunities and health (Cockerham 2007; Kuh et al. 2003; Kuh and Hardy 2002; Mckenzie et al. 2011). Moreover, there is also a need for more comparative longitudinal studies within diverse national contexts which use comparative methodologies, taking into account how different national contexts may mediate the relationship between unemployment and health behaviours. 
Acknowledgments We would like to thank two anonymous reviewers for very helpful comments and advices and William T. Gallo, Carsten Sauer, and Peter Valet for helpful suggestions on earlier versions of the paper.

Conflict of interest The authors declare that they have no conflict of interest.

\section{REFERENCES}

Bambra C, Eikemo TA (2009) Welfare state regimes, unemployment and health: a comparative study of the relationship between unemployment and self-reported health in 23 European countries. J Epidemiol Community Health 63(2):92-98. doi:10.1136/ jech.2008.077354

Bartley M (1988) Unemployment and health: selection or causation - a false antithesis. Sociol Health Illn 10(1):41-67

Bartley MJ, Ferrie J, Montgomery SM (2006) Living in a high unemployment economy: understanding the consequences. In: Marmot M, Wilkinson R (eds) Social determinants of health. Oxford University Press, Oxford

Becker N (2001) Epidemiologic aspects of cancer prevention in Germany. J Cancer Res Clin Oncol 127(1):9-19

Bolton KL, Rodriguez E (2009) Smoking, drinking and body weight after re-employment: does unemployment experience and compensation make a difference? BMC Public Health 9:77. doi:

$10.1186 / 1471-2458-9-77$

Chan TW, Goldthorpe JH (2007) Class and status: the conceptual distinction and its empirical relevance. Am Sociol Rev 72(4): 512-532

Cockerham WC (2007) Social causes of health and disease. Polity Press, Cambridge Cohen G, Duffy JC (2002) Are nonrespondents to health surveys less healthy than respondents. J Off Stat 18(1):13-23 De Vogli R, Santinello M (2005) Unemployment and smoking: does psychosocial stress matter? Tob Control 14(6):389-395. doi:

10.1136/tc.2004.010611

Dickerson SS, Kemeny ME (2004) Acute stressors and cortisol responses: a theoretical integration and synthesis of laboratory research. PsyB 130(3):355-391

Edelen MO, Tucker JS, Ellickson PL (2007) A discrete time hazards model of smoking initiation among West Coast youth from age 5 to 23. Prev Med 44(1):52-54. doi:10.1016/j.ypmed.2006.09.004

Falba T, Teng HM, Sindelar JL, Gallo WT (2005) The effect of involuntary job loss on smoking intensity and relapse. Addiction 100(9):1330-1339. doi:10.1111/j.1360-0443.2005.01150.x

Gallo WT, Teng H, Sindelar J, Falba T (2005) Effect of involuntary job loss on smoking intensity and relapse among older workers. Gerontologist 45:157-159

Graham H (2002) Building an inter-disciplinary science of health inequalities: the example of lifecourse research. Soc Sci Med 55:2005-2016

Hammarstrom A, Janlert U (2003) Unemployment - an important predictor for future smoking: a 14-year follow-up study of school leavers. Scand J Public Health 31(3):229-232. doi:10.1080/ 14034940210164902

Jusot F, Khlat M, Rochereau T, Serment C (2008) Job loss from poor health, smoking and obesity: a national prospective survey in France. J Epidemiol Community Health 62(April):332-337

Kroh M (2010) Documentation of sample sizes and panel attrition in the German Socio-Economic Panel (SOEP). DIW Data Documentation 50:1-49 
Kroll LE, Lampert T (2011) Changing health inequalities in Germany from 1984 to 2008 between employed and unemployed adults. Int J Public Health 56(3):329-339. doi:10.1007/s00038-0110233-0 Kuh D, Hardy R (2002) A life course approach to women's health. Oxford University Press, Oxford Kuh D, Ben-Shlomo Y, Lynch J, Hallqvist J, Power C (2003) Life course epidemiology. J Epidemiol Community Health 57(10): 778-783

Leino-Arjas P, Liira J, Mutanen P, Malmivaara A, Matikainen E (1999) Predictors and consequences of unemployment among construction workers: prospective cohort study. Br Med J 319(7210): 600-605 Link BG, Phelan JC (1996) Understanding sociodemographic differences in health-the role of fundamental social causes. Am J Public Health 86(4):471-473

Long SJ (1997) Regression models for categorical and limited dependent variables. SAGE, Thousand Oaks

Mckenzie SK, Carter KN, Blakely T, Ivory V (2011) Effects of childhood socioeconomic position on subjective health and health behaviours in adulthood: how much is mediated by adult socioeconomic position? BMC Public Health 11:269. doi:

10.1186/1471-2458-11-269

Montgomery SM, Cook DG, Bartley MJ, Wadsworth MEJ (1998) Unemployment, cigarette smoking, alcohol consumption and body weight in young British men. Eur J Public Health 8(1): 21-27

Morris JK, Cook DG, Shaper AG (1992) Nonemployment and changes in smoking, drinking, and body-weight. Br Med J 304(6826):536-541

Osler M (1995) Unemployment and change in smoking behaviour among Danish adults. Tob Control 4(1):53-56

Pearlin LI (1989) The sociological-study of stress. J Health Soc Behav 30(3):241-256

Ryan J, Zwerling C, Jones M (1996) Cigarette smoking at hire as a predictor of employment outcome. J Occup Environ Med 38(9): 928-933

Schneider S (2007) Causes of socioeconomic group-related mortality in the Federal Republic of Germany-tobacco consumption is the predominant risk factor. Int J Public Health 52(1):39-53. doi: 10.1007/s00038-006-5073-y

Schunck R, Rogge BG (2010) Unemployment and its association with health-relevant actions. Investigating the role of time perspective with German census data. Int J Public Health 55(4): 271-278 Siegrist J (2000a) Increased desire to smoke during acute stress. Soc Sci Med 51(9):1283-1293

Siegrist J (2000b) Place, social exchange and health: proposed sociological framework. Soc Sci Med 51(9):1283-1293

Thomas C, Benzeval M, Stansfeld SA (2005) Employment transitions and mental health: an analysis from the British household panel survey. J Epidemiol Community Health 59(3):243-249

Umberson D, Lui H, Reczek C (2008) Stress and health behaviour over the life course. Adv Life Course Res 13:19-44

Virtanen P, Vahtera J, Broms U, Sillanmaeki L, Kivimaeki M, Koskenvuo M (2008) Employment trajectory as determinant of change in health-related lifestyle: the prospective HeSSup study. Eur J Public Health 18(5):504-508. doi:10.1093/eurpub/ckn037

Wagner GG, Frick JR, Schupp J (2007) The German Socio-Economic Panel study (SOEP)—scope, evolution and enhancement. Schmollers Jahrbuch 127(1):139-169

Wooldridge JM (2010) Econometric analysis of cross section and panel data, 2nd edn. MIT Press, Cambridge

Zorn CJW (1998) An analytic and empirical examination of zeroinflated and hurdle Poisson specifications. Sociol Methods Res 26(3):368-400 